\title{
Effects of Supervised Short-Term Exercise Training On Cardiorespiratory Control and Exercise Capacity in Type 2 Diabetes Patients
}

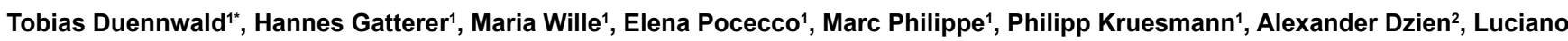
Bernardi $^{3}$ and Martin Burtscher ${ }^{1}$

${ }^{1}$ Department of Sport Science, Medical Section, University of Innsbruck, Austria

${ }^{2}$ Medicalcenter Innsbruck, Innsbruck, Austria

${ }^{3}$ Department of Internal Medicine, University of Pavia and IRCCS San Matteo, Pavia, Italy

\begin{abstract}
Objective:Type 2 diabetes is associated with impaired respiratory and cardiovascular control. Physical exercise training is a well-established tool in the treatment of diabetes. However, effects of short-term exercise training on respiratory control in diabetes are unknown. Thus, we examined the effects of 4 weeks of exercise training (high intensity interval- and continuous moderate exercise training; HIT and CMT) on cardiorespiratory control and aerobic capacity in type 2 diabetes subjects.

Methods: Fifteen non-insulin dependent subjects with type 2 diabetes ( 4 female, 11 male, age $59.6 \pm 1.5$ years, BMI $\left.29.5 \pm 1.0 \mathrm{~kg} / \mathrm{m}^{2}, \mathrm{HbA} 1 \mathrm{C} 7.0 \pm 0.3 \%\right)$ were randomized to either supervised HIT $(\mathrm{N}=8)$ or CMT $(\mathrm{N}=7)$, both equalized for the total amount of work, for 3 times a week over 4 weeks. At baseline and follow up, measurements of hypercapnic and hypoxic ventilatory response (HCVR; HVR), Baroreflex Sensitivity (BRS) and $\mathrm{VO}_{2}$ peak were performed.
\end{abstract}

Results: Four weeks of supervised exercise training increased resting HCVR (from $0.55 \pm 0.1$ to $0.73 \pm 0.1 \mathrm{~L}$ $\left.\mathrm{min} / \mathrm{mmHgCO}_{2-\mathrm{et}}\right)$, whereas HVR and BRS remained unchanged. $\mathrm{VO}_{2}$ peak $(27.5 \pm 1.4$ versus $30.1 \pm 1.6 \mathrm{ml} / \mathrm{kg} / \mathrm{min})$ and $\mathrm{VO}_{2}$ at anaerobic threshold $(19.7 \pm 1.0$ versus $21.9 \pm 1.3 \mathrm{ml} / \mathrm{kg} / \mathrm{min})$ increased in the whole group. No significant changes between HIT and CMT were observed, except a slight increase in haemoglobin concentration after HIT.

Conclusion: Our findings indicate that short-term exercise training increases HCVR associated with an improvement in aerobic capacity in patients with type 2 diabetes. HIT might demonstrate a less time demanding alternative to CMT. These findings are of clinical relevance, as exercise capacity predicts cardiovascular and overall mortality.

Keywords: Diabetes mellitus; Physical exercise; Chemoreflex sensitivity; Autonomic neuropathy; Interval training

Abbreviations: ANS: Autonomic Nervous System; BRS: Baroreflex Sensitivity; CMT : Continuous Moderate Exercise Training; $\mathrm{CO}_{2}$ : Carbon Dioxide: $\mathrm{CO}_{2}$-Et: End-Tidal $\mathrm{CO}_{2}$ : DBP : Diastolic Blood Pressure; FEV1: Forced Expiratory Volume In One Second; FEVC: Forced Expiratory Vital Capacity; FPG : Fasting Plasma Glucose; HCVR: Hypercapnic Ventilatory Response; HDL: High-Density Lipoprotein; HIT : High Intensity Interval Training; HOMA-IR: Homeostasis Model Of Assessment - Insulin Resistance; HR AT: Heart Rate At Anaerobic Threshold; HR Max: Maximum Heart Rate; HVR: Hypoxic Ventilatory Response; $\mathrm{SaO}_{2}$ : Arterial Oxygen Saturation; SBP: Systolic Blood Pressure; SDNN: Standard Deviation Of All RR Intervals; $\mathrm{VO}_{2}$ : Peak Oxygen Uptake; $\mathrm{VO}_{2}$-AT: $\mathrm{VO}_{2}$ At Anaerobic Threshold; VRT- $\mathrm{CO}_{2}$ : Ventilatory Recruitment Threshold To Carbon Dioxide

\section{Introduction}

Type 2 diabetes mellitus is a multifactorial metabolic disorder with a worldwide increasing prevalence [1]. Generally, beneficial effects of structured exercise training in type 2 diabetes patients are well known and fitness level is inversely related to the prevalence of diabetes mellitus [2,3]. However, to our knowledge, the effect of exercise training on respiratory control is unknown. In addition to the known metabolic effects of diabetes, abnormalities of autonomic regulation, which represent one of the most important complications in type 2 diabetes, lead to impaired insulin resistance and predispose to or aggravate renal, cardiac, vascular and/or ocular complications.
Autonomic abnormalities do not seem to originate from anatomical lesions only and might therefore be at least to some extent, reversible by an appropriate intervention, as previously shown by our group [4,5].

In diabetes, chemoreflexes were found to be impaired, showing decreased ventilatory responses to hypoxia (HVR) [6-9] and hypercapnia (HCVR), irrespective of evidenced autonomic neuropathy [8-10]. In addition, baroreflex sensitivity (BRS) was reported to be blunted in these patients [11]. Endurance exercise has previously shown to beneficially affect the autonomic system in patients with cardiovascular diseases [12]. However, studies examining the effects of exercise training on autonomic function in diabetes are scarce and mainly concentrate on measures of cardiovascular control $[13,14]$. To our knowledge, little is known about the effects of short-term endurance exercise on cardiorespiratory control, i.e. HVR, HCVR and BRS in these patients.

*Corresponding author: Tobias Dünnwald, PhD, Department of Sport Science, Medical Section, University of Innsbruck, 6020 Innsbruck, Austria, Tel.:+43-512/ 507 54888; Fax: +43-512/ 507 54999; E-mail: tobias.duennwald@uibk.ac.at

Received July 14, 2014; Accepted August 26, 2014; Published September 03 2014

Citation: Duennwald T, Gatterer H, Wille M, Pocecco E, Philippe M, et al. (2014) Effects of Supervised Short-Term Exercise Training On Cardiorespiratory Control and Exercise Capacity in Type 2 Diabetes Patients. J Diabetes Metab 5: 418 doi:10.4172/2155-6156.1000418

Copyright: (c) 2014 Duennwald T, et al. This is an open-access article distributed under the terms of the Creative Commons Attribution License, which permits unrestricted use, distribution, and reproduction in any medium, provided the original author and source are credited. 
Indeed, international guidelines recommend at least 150 minutes of moderate aerobic activity or even more (30 min, $5 \mathrm{~d} \bullet \mathrm{wk}-1)$ [15]. Yet, there is no clear specification of the exercise training for achieving most beneficial effects, in particular with regard to its effects on autonomic control. In order to maintain adequate glycemic control, the optimal type of exercise (e.g. aerobic or resistance exercise) is still under debate [16]. With regard to aerobic exercise both, Continuous Moderate Exercise Training (CMT) and High Intensity Interval Training (HIT), have been shown to improve glucose metabolism [2,17]. Although exercise intensity has been demonstrated to be a better predictor for total blood glucose control than exercise volume, only a few studies evaluated the effects of HIT in type 2 diabetes patients, without providing information about the effects on respiratory control $[2,17,18]$.

Thus, the present study was designed to examine the effects of supervised short-term aerobic exercise training on cardiovascular and respiratory control and on aerobic capacity in type 2 diabetes subjects. We primarily hypothesized that a 4 -week supervised training intervention would improve chemo- and baroreflex sensitivity and $\mathrm{VO}_{2}$ peak in patients with type 2 diabetes. An additional but only secondary objective was to evaluate possible diverging effects of HIT and CMT.

\section{Methods}

\section{Subjects}

Fifteen type- 2 diabetes subjects (4 female, 11 male) aged 50 - 65 years were invited to participate in the study. Patients were recruited through general practitioners in the area of Innsbruck $(550 \mathrm{~m})$, Austria. Exclusion criteria were the presence of exercise-limiting pulmonary or musculoskeletal diseases, unstable diabetes, prior or acute myocardial infarction, proliferative retinopathy, cardiovascular complications, ventricular arrhythmias and artrial fibrillation, smoking, insulin treatment, severe hypertension, unstable or stable angina or other comorbidities which didn't allow to persist the exercise program. All medications were recorded before and after the intervention. The majority of the subjects $(n=12)$ was treated with oral anti hyperglycaemic agents and 3 were unmedicated (diet-controlled diabetes). Participants were asked not to modify their habits concerning medications, nutrition and extent of physical activity. In order to avoid baseline differences in performance levels between groups, the allocation to one of the two training groups, either HIT $(n=8)$ or CMT $(n=7)$, was accomplished by cluster randomization. Baseline data was compared to the data obtained by 10 healthy age-matched controls (age $51.8 \pm 2.4$ years, height $1.73 \pm 0.02 \mathrm{~m}$, BMI $22.6 \pm 0.5 \mathrm{~kg} / \mathrm{m}^{2} \mathrm{HCVR}$ $0.88 \pm 0.13 \mathrm{Lmin}^{-1} / \mathrm{mmHgCO}_{2}-$ ET, HVR $0.65 \pm 0.97 \mathrm{Lmin}^{-1} \% \mathrm{SaO}_{2}$, Ventilatory recruitment threshold to carbon dioxide $\left(\mathrm{VRT}-\mathrm{CO}_{2}\right) 37.7 \pm$ $\left.1.4 \mathrm{mmHg}, \mathrm{SaO}_{2} 97.0 \pm 0.4 \%\right)$. The study was carried out in accordance with the Declaration of Helsinki 1978 and was approved by the Ethics Committee of the Medical University of Innsbruck. All subjects gave written informed consent at the beginning of the study.

\section{Study protocol}

Anthropometric data: Baseline and follow up measurements have been performed by physicians and exercise physiologists at the same daytime. Body height $(\mathrm{cm})$ and weight $(\mathrm{kg})$ were measured in a standardized manner using calibrated devices.

Exercise testing: At the beginning and in the end of the intervention, an incremental symptom-limited spiroergometric test was performed on a bicycle ergometer (Ergoline 900, Schiller, Switzerland). Resting heart rate and systemic blood pressure were measured in a sitting position during a resting period before the start of the test. The initial workload was 25 watts with an increase of 25 watts every 2 minutes. Patients were instructed to keep a pedal rate between 70 and $80 \mathrm{rpm}$. Heart rate was continuously recorded via a 6-lead electrocardiogram, and the measurements of blood pressure and blood lactate concentration (Biosen 5040, Magdeburg, Germany) were performed at the end of each workload. Respiratory gas analysis was performed using an open spirometric system (Oxycon Alpha, Jaeger, Germany). $\mathrm{VO}_{2 \text { peak }}$ peak was defined as the highest $\mathrm{VO}_{2}$ averaged over 30 seconds before exhaustion. The highest $\mathrm{HR}$ achieved in the test was set as $\mathrm{HR}_{\max }$, whereas $\mathrm{HR}_{\mathrm{AT}}$ illustrates the heart rate at the anaerobic threshold. The exercise test was terminated when participants discontinued due to exhaustion (pedal rate $<40 \mathrm{rpm}$ ).

Testing of cardiovascular and respiratory control: In order to test chemoreflex sensitivity, HVR and HCVR were measured each on two different days under standardized conditions with a 3-5 day interval in between before and after the training intervention. The mean of the two regression slopes was taken for analysis. Measurements were performed in the morning $2 \mathrm{~h}$ after a light breakfast in a supine position in a temperature controlled and silent room. Patients were advised to abstain from caffeinated beverages for $12 \mathrm{~h}$ and from alcohol for $36 \mathrm{~h}$ before the investigations. Subjects were connected to a rebreathing circuit using a mouthpiece, as previously described $[19,20]$. We continuously measured end-tidal $\mathrm{CO}_{2}\left(\mathrm{CO}_{2}\right.$-et $)$ using a capnograph connected to a mouthpiece (COSMO plus, Novametrix, Wallingford, Connecticut, USA) and oxygen saturation $\left(\mathrm{SaO}_{2}\right)$ using a pulse oxymeter (3740 Ohmeda, Englewood, Colorado, USA). A heated Fleish pneumotachograph (Metabo, Epalinges, Switzerland) in connection to a differential pressure transducer (RS part N395-257; Corby, UK) was applied for continuously measuring airway flow. ECG was recorded using 3 chest leads and blood pressure was monitored continuously by a digital plethysmograph (Finapres 2300; Ohmeda, Louisville, Co, USA).

For the testing of $\mathrm{HVR}, \mathrm{CO}_{2}$-et pressure was held constant at the resting $\mathrm{CO}_{2}$-et value of each individual subject by releasing a fraction of the exhaled air into a scrubbing circuit (filled with soda lime) before returning it to the rebreathing bag. The test was completed when arterial oxygen saturation $\left(\mathrm{SaO}_{2} \%\right)$ dropped below $80 \%$. In order to measure $\mathrm{HCVR}, \mathrm{SaO}_{2} \%$ was maintained constant at baseline levels ( $>95 \%)$, permanently supplying oxygen to the circuit before starting the rebreathing. An increase from baseline $\mathrm{CO}_{2}$-et to $13 \mathrm{mmHg} \mathrm{CO}_{2}-$ et above baseline was set as termination criteria for the test. Resting data was obtained prior to each rebreathing test during 4 minutes of spontaneous breathing of room air.

Data acquisition and analysis: Signals from ECG, blood pressure, pneumotachograph, carbon dioxide and $\mathrm{SaO}_{2}$ were transmitted online to a personal computer (Apple Macintosh G3, Coupertino, California, USA) at 600 samples/channel. The signal from ventilatory flow was integrated by software and an automatic and interactive program written in BASIC by one of our group members (L.B.) was applied to identify every single breath.

Measurement of chemoreflex sensitivity: The slopes of the linear regression of minute ventilation vs. $\mathrm{SaO}_{2}$ or $\mathrm{CO}_{2}$-et reflect the chemoreflex sensitivity to hypoxia and hypercapnia, respectively. The response to $\mathrm{CO}_{2}$-et is predominantly considered as an index of central chemoreflex activity, whereas the response to hypoxia is mainly considered as an indicator of peripheral chemoreflex activity. The "ventilatory recruitment threshold" [VRT- $\mathrm{CO}_{2}$ ] describes the point at which the ventilation started to increase during the testing of the hypercapnic ventilatory response. VRT- $\mathrm{CO}_{2}$ was identified by interpolating the ventilation/ $/ \mathrm{CO}_{2}$-et plot using a 4th-order polynomial function. 
Measurement of baroreflex sensitivity: Before and after the exercise program BRS was measured during recordings on spontaneous breathing on two separate days, respectively, with the mean value of the two measurements entering the analysis. Time series of RR interval (from each of 2 consecutive $\mathrm{R}$ waves of the electrocardiogram) and Systolic Blood Pressure (SBP) were received from the original data. As previous studies have shown a low correlation between different indices of BRS, and no method has shown clear superior performance over the other, the average of a set of 7 different tests was computed: positive and negative sequence methods, the alpha coefficient in the low and high frequency bands and its average, the transfer function technique, and the ratio of standard deviations of RR interval and systolic blood pressure variabilities [21-25].

In addition to the BRS, the Standard Deviation of the RR Interval (SDNN) as a global index of heart rate variability was assessed. This variable has a more normal distribution when compared to other indices of variability (e.g. variance).

Exercise training: All subjects participated in a standardized and supervised exercise training program on a bicycle ergometer 3 times a week for 4 weeks. The High Intensity Interval Training (HIT) started with a 7 minute warm up at $70 \%$ of maximal heart rate (HR max; $60 \%$ $\mathrm{VO}_{2}$ peak [26]) in the beginning and continued with five 4-minute intervals at $90-95 \%$ of $\mathrm{HR} \max \left(85 \% \mathrm{VO}_{2}\right.$ peak [26]) with an active recovery of 3 minutes of cycling at $70 \%$ of $\mathrm{HR} \max \left(60 \% \mathrm{VO}_{2}\right.$ peak). The training was completed by a 3-minute cool down phase at $70 \%$ of HR max, resulting in a total exercise time of 42 minutes. In order to equalize the total amount of work for both training groups, total $\mathrm{VO}_{2}$-time relationship for the HIT group was divided by the intensity previously defined for the CMT group (60\% $\mathrm{VO}_{2}$ peak). Therefore, the calculated duration of exertion for the CMT group was 50.3 minutes at a moderate intensity of $70 \%$ of $\mathrm{HRmax}\left(60 \% \mathrm{VO}_{2}\right.$ peak). The application of pre-defined training intensities for both groups was continuously controlled by heart rate monitoring. The evaluation of the rate of perceived exertion according to the Borg scale [27] was performed at the end of each exercise session.Workloads were regularly adapted in order to maintain the prescribed training loads.
Blood analyses: Capillary blood has been sampled from the hyperaemized fingertip by means of heparinized glass capillaries after $10 \mathrm{~h}$ of overnight fasting. Fasting Plasma Glucose (FPG), serum creatinine, glycated hemoglobin $\left(\mathrm{HbA}_{1 \mathrm{C}}\right)$, total serum cholesterol, High Density Lipoprotein (HDL) and hemoglobin were determined using standard local procedures (Reflotron ${ }^{\star}$ sprint, Boehringer Mannheim, Germany; Miniphotometer LP 20, Dr. Lange, Germany), before and after each exercise session. Non-fasting glucose levels were obtained from capillary blood (Multicare In-Vitro Diagnostic System; Biochemical System). Changes due to training were calculated as post minus pre values $(\Delta)$.

Statistical analysis: A 2-way analysis of variance for repeated measurements was applied in order to evaluate main effects (time: effects of training within the overall sample; group: effects of training modality), and interaction effects (time $\mathrm{x}$ group). Significant interaction effects were followed by post-hoc procedures (t-test). Within group changes with respect to baseline were evaluated by paired Student's t-tests. In order to determine the relation between individual variables, Pearson's correlation coefficient was computed. To estimate the distribution normality of the variables, the Kolmogorov-Smirnovtest (KS-Test) was used. Percentage changes in plasma volume were calculated applying the equation derived from Dill and Costill [28]. In order to evaluate the effect of training on non-fasting glucose levels, $\Delta$ mean values for each training week (3 training days per week) were calculated and then analysed using a 2-way Anova. Differences between groups at baseline were analysed by means of unpaired t-test. Statistical significance was set at a $\mathrm{p}$-value $<0.05$ (two-tailed). Analysis of the collected data was accomplished using the SPSS statistical-software package 18. All data are presented as means \pm Standard Error of the Mean (SEM)

\section{Results}

Baseline characteristics of the whole study sample are presented in Table 1. No significant differences were observed in any of the measured variables between sub-groups (HIT, CMT) at baseline. All participants performed each of the 12 prescribed training sessions. The training program was well tolerated and accomplished without any

\begin{tabular}{|c|c|c|c|c|}
\hline & Whole Sample & & & \\
\hline & $(n=15)$ & HIT-Group (n=8) & CMT-Group (n=7) & \\
\hline & Mean ( \pm SEM) & Mean ( \pm SEM) & Mean ( \pm SEM) & $p$ value \\
\hline Gender $(M / F)$ & $11 / 4$ & $6 / 2$ & $5 / 2$ & \\
\hline Age (years) & $59.6 \pm 1.5$ & $59.6 \pm 2.0$ & $59.6 \pm 2.3$ & 0.98 \\
\hline Height $(\mathrm{cm})$ & $174.5 \pm 1.5$ & $174.3 \pm 2.6$ & $174.7 \pm 1.5$ & 0.82 \\
\hline Weight (kg) & $90.2 \pm 3.7$ & $84.9 \pm 4.6$ & $96.1 \pm 5.3$ & 0.13 \\
\hline Body mass index $\left(\mathrm{kg} / \mathrm{m}^{2}\right)$ & $29.5 \pm 1.0$ & $27.8 \pm 1.0$ & $31.5 \pm 1.6$ & 0.07 \\
\hline Systolic blood pressure (mmHg) & $130 \pm 2$ & $130 \pm 3$ & $131 \pm 3$ & 0.86 \\
\hline Diastolic blood pressure $(\mathrm{mmHg})$ & $79 \pm 1$ & $78 \pm 2$ & $80 \pm 2$ & 0.36 \\
\hline Resting heart rate (beat/min) & $82 \pm 3$ & $81 \pm 2$ & $82 \pm 7$ & 0.41 \\
\hline Waist-to-hip ratio & $1.05 \pm 0.3$ & $1.05 \pm 0.3$ & $1.04 \pm 0.1$ & 0.71 \\
\hline Duration of diabetes (years) & $9 \pm 1$ & $11 \pm 2$ & $7 \pm 2$ & 0.12 \\
\hline Serum creatinine $(\mu \mathrm{mol} / \mathrm{l})$ & $0.86 \pm 0.3$ & $0.90 \pm 0.1$ & $0.81 \pm 0.4$ & 0.73 \\
\hline $\mathrm{FEV}_{1}(\mathrm{~L})$ & $3.5 \pm 0.1$ & $3.8 \pm 0.2$ & $4.1 \pm 0.1$ & 0.47 \\
\hline FEVC (L) & $3.9 \pm 0.2$ & $3.6 \pm 0.3$ & $3.5 \pm 0.3$ & 0.97 \\
\hline $\mathrm{FEV}_{1} / \mathrm{FVC}(\%)$ & $90.0 \pm 3.0$ & $93.0 \pm 5.2$ & $86.5 \pm 2.2$ & 0.29 \\
\hline
\end{tabular}

Data are presented as mean \pm SEM. Forced expiratory volume in 1 second (FEV $)$, Forced expiratory vital capacity (FEVC). $\mathrm{P}$ value (unpairedt-test) for differences between HIT and CMT group

Table 1: Baseline characteristics of the study population. 
complications by participants of HIT and CMT. Overall, all 15 study subjects completed the 4 -week exercise intervention. No correlations were found among the measured parameters.

\section{Data on respiratory and cardiovascular control}

At baseline, diabetes patients showed significant lower HCVR and higher VRT- $\mathrm{CO}_{2}$ as compared to the control group $(0.55 \pm 0.1$ versus $0.88 \pm 0.13 \mathrm{~L} / \mathrm{min} / \mathrm{mmHg} \mathrm{CO}$-ET; $\mathrm{p}=0.03$ and $41.5 \pm 0.6$ versus $37.7 \pm$ $1.4 \mathrm{mmHg} ; \mathrm{p}=0.04$, respectively), and baseline oxygen saturation was lower when compared to the healthy control group ( $94.7 \pm 0.4$ versus $97.0 \pm 0.4 \% ; \mathrm{p}=0.05)$. Respiratory and cardiovascular changes are presented in Figure 1 and Table 2, respectively. In the whole group the HCVR increased significantly significantly from baseline to follow up $\left(0.55 \pm 0.1\right.$ versus $\left.0.73 \pm 0.1 \mathrm{~L} / \mathrm{min} / \mathrm{mmHgCO}_{2}-\mathrm{ET}\right)$ within the overall sample (time effect: $\mathrm{p}=0.04 ; \mathrm{F}=5.0$ ) but there was no significant time $\mathrm{x}$ group interaction. HVR, VRT-CO ${ }_{2}$, BRS, RR-interval, SDNN, BPsys ${ }_{\text {REST }}, \mathrm{BPdia}_{\mathrm{REST},} \mathrm{HR}_{\mathrm{REST}}$ and $\mathrm{SaO} 2$ remained unchanged (no significant main or interaction effects) Only VRT- $\mathrm{CO}_{2}$ tended to be different between HIT and CMT ( $\mathrm{p}=0.06$ for time $\mathrm{x}$ group interaction).

\section{Exercise data}

Changes in exercise parameters are presented in Table 2. After four weeks of supervised exercise training, $\mathrm{VO}_{2}$ peak increased by $9.5 \%$ in the overall sample (time effect: $\mathrm{p}<0.05 ; \mathrm{F}=30.3$ ) without significant time $\times$ group interaction. $\mathrm{VO}_{2}-\mathrm{AT}$ increased by $11.2 \%$ in the overall sample (time effect: $\mathrm{p}<0.05 ; \mathrm{F}=14.6$ ) and showed a trend for a time $\times$ group interaction $(\mathrm{p}=0.10 ; \mathrm{F}=2.8) . \mathrm{HR}_{\max }$ tended to be higher after the intervention $(\mathrm{p}=0.07 ; \mathrm{F}=3.8)$ without significant time $\times$ group interaction. Average rating of perceived exertion after training did not differ between HIT and CMT (13.3 \pm 0.5 versus $12.6 \pm 0.2 ; \mathrm{p}=0.25)$.

\section{Anthropometric and blood data}

Effects of the training intervention on anthropometric and blood
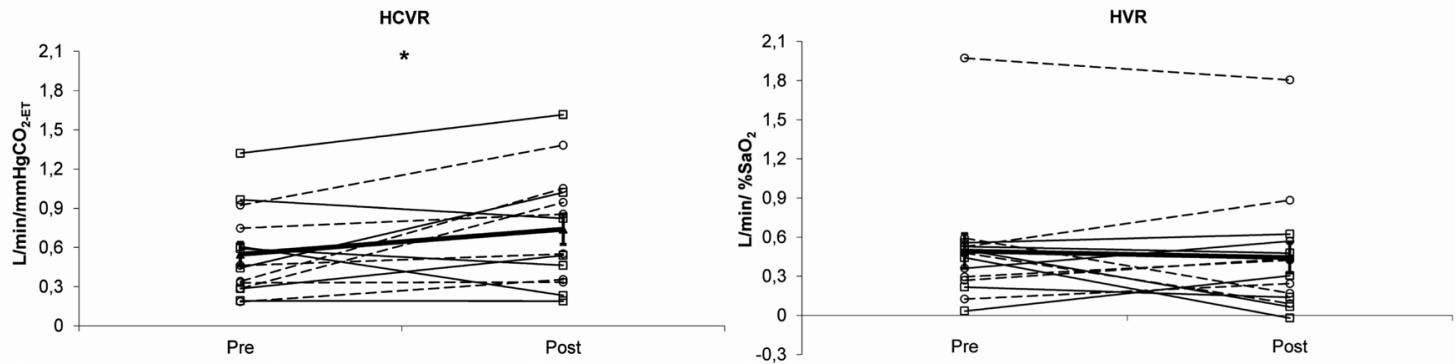

Figure 1: Hypoxic and hypercapnic ventilatory response to the training intervention

Changes of the whole sample are shown comprising high intensity interval- (HIT) [ $\square]$ and Continuous Moderate Exercise Training (CMT) [o]. Mean values and standard errors for the whole sample are presented as bold lines. Hypercapnic Ventilatory Response (HCVR) significantly increased whereas Hypoxic Ventilatory Response (HVR) remained unchanged during the 4-week exercise intervention. *time effect: $p<0.05$ in comparison to baseline values.

\begin{tabular}{|c|c|c|c|c|c|c|c|c|c|c|}
\hline & & & & & \multicolumn{6}{|c|}{ ANOVA } \\
\hline & \multicolumn{2}{|c|}{ HIT Group(n=8) } & \multicolumn{2}{|c|}{ CMT-Group $(n=7)$} & \multirow{2}{*}{\multicolumn{2}{|c|}{$\begin{array}{c}\text { (main effect) } \\
\text { training }\end{array}$}} & \multirow{2}{*}{\multicolumn{2}{|c|}{$\begin{array}{c}\text { (main effect) } \\
\text { group }\end{array}$}} & \multirow{2}{*}{\multicolumn{2}{|c|}{$\begin{array}{c}\text { (interaction) } \\
\text { time } x \text { group }\end{array}$}} \\
\hline & \multirow{2}{*}{$\begin{array}{c}\text { Mean ( } \pm \text { SEM) } \\
\text { Baseline }\end{array}$} & \multirow{2}{*}{\begin{tabular}{|c|} 
Mean ( \pm SEM) \\
Follow-up
\end{tabular}} & \multirow{2}{*}{$\begin{array}{c}\text { Mean ( } \pm \text { SEM) } \\
\text { Baseline }\end{array}$} & \multirow{2}{*}{$\begin{array}{c}\text { Mean ( } \pm \text { SEM) } \\
\text { Follow-up }\end{array}$} & & & & & & \\
\hline & & & & & $P$-value & F-value & $P$-value & F-value & P-value & F-value \\
\hline \multicolumn{11}{|c|}{ Respiratory and cardiovascular parameters } \\
\hline $\mathrm{HCVR}\left(\mathrm{L} / \mathrm{min} / \mathrm{mmHgCO}_{2-\mathrm{ET}}\right)$ & $0.63 \pm 0.4$ & $0.70 \pm 0.5$ & $0.47 \pm 0.3$ & $0.78 \pm 0.4$ & 0.04 & 4.96 & 0.85 & 0.03 & 0.34 & 2.21 \\
\hline $\operatorname{HVR}\left(\mathrm{L} / \mathrm{min} / \% \mathrm{SaO}_{2}\right)$ & $0.37 \pm 0.1$ & $0.29 \pm 0.1$ & $0.62 \pm 0.2$ & $0.60 \pm 0.2$ & 0.53 & 0.42 & 0.25 & 1.48 & 0.70 & 0.16 \\
\hline VRT-CO $(\mathrm{mmHg})$ & $41.8 \pm 0.9$ & $40.8 \pm 0.7$ & $41.7 \pm 0.7$ & $2.0 \pm 0.7$ & 0.80 & 0.67 & 0.78 & 0.08 & 0.06 & 4.52 \\
\hline $\mathrm{BRS}(\mathrm{ms} / \mathrm{mmHg})$ & $8.1 \pm 1.2$ & $7.3 \pm 0.8$ & $6.6 \pm 0.7$ & $8.3 \pm 0.5$ & 0.75 & 0.11 & 0.28 & 0.13 & 0.36 & 0.92 \\
\hline $\mathrm{RR}(\mathrm{ms})$ & $900.3 \pm 29.3$ & $902.1 \pm 31.7$ & $885.2 \pm 36.2$ & $920.1 \pm 33.2$ & 0.18 & 2.06 & 0.42 & 0.69 & 0.29 & 1.24 \\
\hline SDNN (ms) & $37.8 \pm 6.5$ & $30.2 \pm 2.5$ & $32.4 \pm 4.8$ & $32.5 \pm 4.1$ & 0.43 & 2.81 & 0.76 & 0.99 & 0.12 & 2.81 \\
\hline BPsys $_{\text {REST }}(\mathrm{mmHg})$ & $130 \pm 3$ & $124 \pm 2$ & $131 \pm 3$ & $127 \pm 3$ & 0.11 & 2.72 & 0.46 & 0.59 & 0.66 & 0.20 \\
\hline BPdia $_{\text {REST }}(\mathrm{mmHg})$ & $78 \pm 1$ & $76 \pm 2$ & $80 \pm 2$ & $76 \pm 2$ & 0.07 & 4.14 & 0.65 & 0.22 & 0.29 & 1.25 \\
\hline $\mathrm{HR}_{\text {REST }}(\mathrm{b} / \mathrm{min})$ & $81 \pm 2$ & $81 \pm 4$ & $82 \pm 7$ & $79 \pm 4$ & 0.45 & 0.56 & 0.95 & 0.01 & 0.66 & 0.20 \\
\hline $\mathrm{SaO}_{2}(\%)$ & $94.6 \pm 0.5$ & $94.3 \pm 0.5$ & $94.7 \pm 0.7$ & $94.9 \pm 0.4$ & 0.98 & 0.00 & 0.33 & 1.09 & 0.34 & 1.01 \\
\hline \multicolumn{11}{|l|}{ Exercise parameters } \\
\hline $\mathrm{VO}_{2 \text { peak }}(\mathrm{ml} / \mathrm{kg} / \mathrm{min})$ & $28.3 \pm 1.9$ & $31.4 \pm 2.2$ & $26.6 \pm 2.0$ & $28.5 \pm 2.2$ & $<0.001$ & 30.31 & 0.45 & 0.60 & 0.19 & 1.80 \\
\hline Workload (watt/kg) & $2.11 \pm 0.2$ & $2.4 \pm 0.2$ & $1.90 \pm 0.2$ & $2.1 \pm 0.2$ & $<0.001$ & 31.14 & 0.29 & 1.21 & 0.43 & 0.67 \\
\hline $\mathrm{VO}_{2-\mathrm{AT}}(\mathrm{ml} / \mathrm{kg} / \mathrm{min})$ & $20.4 \pm 1.5$ & $23.4 \pm 41.7$ & $19.0 \pm 1.4$ & $20.1 \pm 1.7$ & 0.002 & 14.55 & 0.30 & 1.16 & 0.10 & 2.84 \\
\hline $\mathrm{HR}_{\mathrm{AT}}(\mathrm{bpm})$ & $123 \pm 3$ & $130 \pm 7$ & $121 \pm 7$ & $121 \pm 6$ & 0.21 & 1.58 & 0.50 & 0.48 & 0.21 & 1.70 \\
\hline $\mathrm{HR}_{\max }(\mathrm{bpm})$ & $152 \pm 6$ & $164 \pm 7$ & $153 \pm 6$ & $153 \pm 4$ & 0.07 & 3.83 & 0.56 & 0.38 & 0.09 & 3.29 \\
\hline
\end{tabular}

Data are presented as mean \pm SEM. Ventilatory recruitment threshold to $\mathrm{CO}_{2}\left(\mathrm{VRT}-\mathrm{CO}_{2}\right)$, baroreflex sensitivity (BRS), standard deviation of all R-R intervals (SDNN), systolic blood pressure at rest $\left(\mathrm{BPsys}_{\mathrm{REST}}\right)$, diastolic blood pressure at rest $\left(\mathrm{BPdia}_{\mathrm{REST}}\right)$, resting heart rate $\left(\mathrm{HR}_{\mathrm{REST}}\right)$, oxygen saturation $\left(\mathrm{SaO} \mathrm{O}_{2}\right)$. Maximal oxygen uptake $\left(\mathrm{VO}_{2 \text { eak }}\right)$, anaerobic threshold (AT), maximal heart rate $\left(\mathrm{HR}_{\text {max }}\right)$

Table 2: Changes inrespiratory, cardiovascular and exercise parameters from baseline to follow up. 
data are shown in Table 3. Hemoglobin concentration changed over time in the overall sample (time effect: $\mathrm{p}=0.01 ; \mathrm{F}=11.1$ ) and showed a significant time $\mathrm{x}$ group interaction $(\mathrm{p}=0.04 ; \mathrm{F}=5.3) . \mathrm{HbA}_{1 \mathrm{C}}, \mathrm{FPG}$, HOMA-IR, cholesterol, HDL body mass and BMI remained all unchanged. Calculated changes in plasma volume did not differ between HIT $(-5.5 \pm 1.4 \%)$ and CMT $(-2.3 \pm 1.6 \%$; $=0.15 ; \mathrm{F}=0.4$ for time $\mathrm{x}$ group interaction) as well.

\section{Exercise related changes in non-fasting plasma glucose values}

Mean values of non-fasting plasma glucose from all 4 weeks of HIT and CMT are illustrated in Figure 2. Mean non-fasting plasma glucose levels dropped during each exercise training session $(\mathrm{p}<0.05)$. For the $\Delta$ mean values calculated for each training week (week 1-4), no time effect and no time $\mathrm{x}$ group interaction were observed. There were no changes in medication during the intervention period.

\section{Discussion}

\section{Main findings}

The present study demonstrated significant increases in HCVR and aerobic capacity after 4 weeks of supervised exercise training in type 2 diabetes patients independent of training modality, i.e. HIT and CMT.

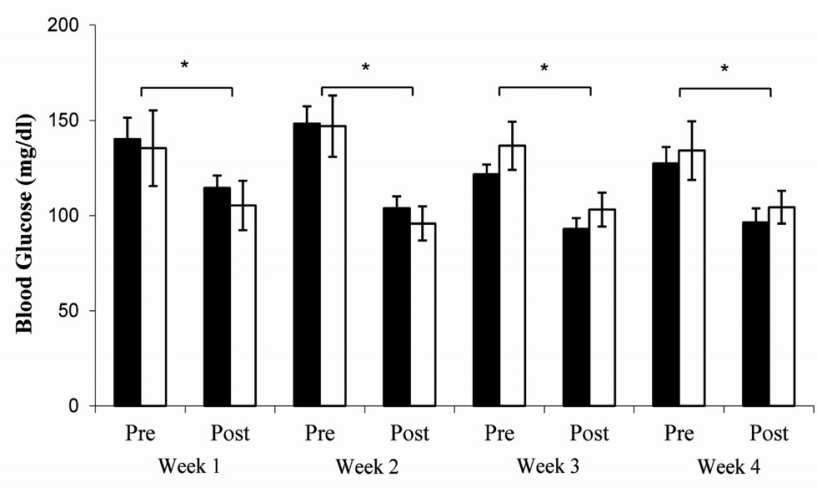

Figure 2: Mean plasma glucose values and standard errors from week 1 to week 4

Black bars represent High Intensity Interval- (HIT) and white bars Continuous Moderate Exercise Training (CMT). Plasma glucose continuously decreased after each training session ( $\Delta$ values, ${ }^{*} P \leq 0.05$ ) without between group changes ( $p$ for time $x$ group interaction)

\section{Respiratory and cardiovascular control}

To our knowledge, this is the first study to examine the effects of regular exercise training on chemoreflex sensitivity in type 2 diabetes patients. In experimental diabetes, Harthmann et al. [29] assessed improved chemoreflex sensitivity after physical exercise. The chemoreflex is a known regulator of blood gases and oxygen delivery. Some authors proposed defective respiratory reflexes to be causative for unexplained cardiorespiratory arrests in diabetes patients with autonomic neuropathy $[10,30]$.

Our observations of reduced HCVR in the diabetes subjects at baseline are in line with the findings of previous studies $[5,6,9,10]$. Baseline VRT- $\mathrm{CO}_{2}$ was higher in the diabetic patients as compared to the healthy controls, implying that a higher $\mathrm{PaCO}_{2}$ is needed to start ventilation. In addition, we observed lower baseline oxygen saturation in the diabetes participants.

In the present study, we demonstrate that 4 weeks of exercise training induced a significant increase in HCVR in patients with type 2 diabetes. Improving the ventilatory response in diabetes patients might potentially reduce hypoxia and therewith the risk of severe diabetes complications.

In contrast to a previous study by Loimaala et al. [14], reporting improved BRS after 12 month of regular exercise training in patients with type 2 diabetes and even after 2 weeks of physical exercise in patients with uncomplicated coronary artery disease [12], we did not see any improvements in cardiovascular control. A likely explanation is that our intervention whilst able to induce an improvement in respiratory reflexes, was yet too short to improve BRS in our diabetic patients.

\section{Aerobic exercise capacity}

Generally, the measurement of $\mathrm{VO}_{2}$ peak is implemented as a standard method determining exercise capacity and cardiorespiratory fitness in healthy and diseased individuals respectively [31]. Cardiorespiratory fitness is mostly reduced in diabetes patients [2]. Due to the relationship between exercise capacity and increased morbidity and mortality in people with diabetes mellitus, there is growing interest in the assessment and improvement of $\mathrm{VO}_{2}$ peak in those patients [32].

The demonstrated findings of increased exercise capacity after HIT $(+11 \%)$ and after CMT $(+7 \%)$ are in line with previous studies reporting $\mathrm{VO}_{2}$ peak increases up to $12 \%$ after higher intensity training and of about $9.5 \%$ after moderate intensity training [2]. Several studies

\begin{tabular}{|c|c|c|c|c|c|c|c|c|c|c|}
\hline & & & & & \multicolumn{6}{|c|}{ ANOVA } \\
\hline & \multicolumn{2}{|c|}{ HIT-Group $(n=8)$} & \multicolumn{2}{|c|}{ CMT-Group (n=7) } & \multirow{2}{*}{\multicolumn{2}{|c|}{$\begin{array}{c}\text { (main effect) } \\
\text { training }\end{array}$}} & \multirow{2}{*}{\multicolumn{2}{|c|}{$\begin{array}{c}\text { (main effect) } \\
\text { group }\end{array}$}} & \multirow{2}{*}{\multicolumn{2}{|c|}{$\begin{array}{c}\text { (interaction) } \\
\text { (time } x \text { group) }\end{array}$}} \\
\hline & Mean ( \pm SEM) & Mean ( \pm SEM) & Mean ( \pm SEM) & Mean ( \pm SEM) & & & & & & \\
\hline & Baseline & Follow-up & Baseline & Follow-up & $P$-value & F-value & $P$-value & F-value & $P$-value & F-value \\
\hline Weight (kg) & $84.9 \pm 1.6$ & $84.9 \pm 4.7$ & $96.1 \pm 5.3$ & $96.0 \pm 5.3$ & 0.29 & 1.07 & 0.13 & 2.60 & 0.58 & 0.33 \\
\hline BMI $\left(\mathrm{kg} / \mathrm{m}^{2}\right)$ & $27.8 \pm 1.0$ & $27.7 \pm 1.1$ & $31.5 \pm 1.6$ & $31.6 \pm 1.7$ & 0.96 & 0.01 & 0.07 & 4.01 & 0.35 & 0.96 \\
\hline $\mathrm{HbA}_{1 \mathrm{C}}(\%)$ & $7.1 \pm 0.3$ & $7.4 \pm 0.3$ & $6.9 \pm 0.5$ & $7.0 \pm 0.4$ & 0.07 & 3.55 & 0.78 & 0.09 & 0.41 & 0.71 \\
\hline FPG (mg/dl) & $139.4 \pm 11.1$ & $146.3 \pm 11.7$ & $128.6 \pm 13.4$ & $129.9 \pm 15.9$ & 0.52 & 0.38 & 0.44 & 0.63 & 0.69 & 0.17 \\
\hline HOMA-IR & $6.4 \pm 2.0$ & $7.2 \pm 4.6$ & $9.1 \pm 2.9$ & $11.4 \pm 3.5$ & 0.50 & 0.51 & 0.24 & 1.56 & 0.73 & 0.12 \\
\hline $\mathrm{CHOL}(\mathrm{mg} / \mathrm{dl})$ & $177 \pm 11$ & $185 \pm 21$ & $177 \pm 18$ & $168 \pm 15$ & 0.99 & 0.01 & 0.60 & 0.28 & 0.38 & 1.50 \\
\hline $\mathrm{HDL}(\mathrm{mg} / \mathrm{dl})$ & $50 \pm 4$ & $53 \pm 5$ & $44 \pm 3$ & $41 \pm 3$ & 0.78 & 0.03 & 0.08 & 3.52 & 0.09 & 3.33 \\
\hline Hemoglobin (g/dl) & $13.7 \pm 0.5$ & $14.1 \pm 0.5^{\star}$ & $14.5 \pm 0.4$ & $14.6 \pm 0.4$ & 0.01 & 11.07 & 0.35 & 0.93 & 0.04 & 5.25 \\
\hline
\end{tabular}

Data are presented as mean \pm SEM. *Significant changes within the group. Body mass index $(\mathrm{BMI})$, glycosylated hemoglobine $\left(\mathrm{HbA} \mathrm{AC}_{1 \mathrm{C}}\right)$ fasting plasma glucose $(\mathrm{FPG})$, homeostasis model of assessment-insulin resistance (HOMA-IR), total serum cholesterol (CHOL), high-density lipoprotein cholesterol (HDL)

Table 3: Changesin anthropometric and blood data from baseline to follow up. 
indicate that higher training intensities are related to larger gains in $\mathrm{VO}_{2}$ peak [2]. However, many diabetes patients may not tolerate high exercise intensities of longer duration. Contrary to continuous exercise, interval training enables individuals to perform short working episodes at higher intensities alternating with phases of active recovery. Thus, current investigations highlight a more pronounced effect of high intensity interval exercise compared to the common used moderate intensities in endurance training. Such an effect was demonstrated in healthy subjects, in patients with postinfarction heart failure and metabolic syndrome [33-35].

In the present study, we observed a trend towards a higher increase in anaerobic threshold after HIT, suggesting a more pronounced effect of HIT on aerobic work capacity compared to CMT. Prolonging the duration of the training intervention might strengthen this effect, as the importance of the duration of an intervention was demonstrated for instance by Moholdt et al. [36]. They observed increases in $\mathrm{VO}_{2}$ peak in the interval but not in the continuous group after 6 month, whereas after 4 weeks changes in the two training groups were similar. Interval training was well tolerated by the type 2 diabetes patients in our study. As the total amount of work was matched in HIT and CMT, HIT was less time demanding as compared to CMT. Irrespective of the training modality, participants felt similar exertion as demonstrated by the same average Borg rates of the two exercise groups, which can be explained by the active recovery phases of lower intensity between the intensive intervals in the HIT group.

\section{Blood glucose and metabolic control}

We observed a significant decrease in mean non-fasting plasma glucose levels during each exercise training session. Without changes between HIT and CMT. These changes indicate that both exercise methods induce similar glucose declines during the particular activity phases. The extent of decline did not change throughout the entire exercise intervention, being in line with the unchanged $\mathrm{HbA}_{1 \mathrm{C}}$ values after the 4 week intervention. However, in implementing a prolonged exercise period, Bweir et al. [37] demonstrated significant reductions in weekly mean pre- and post-exercise glucose values in consequence of a 10 week exercise intervention.

The absence of changes in $\mathrm{HbA}_{1 \mathrm{C}}$ is most likely due to the relatively short duration in our study. Snowling et al. [38] found higher reductions in glycosylated hemoglobin levels in exercise interventions lasting $\geq 12$ weeks compared to $<12$ weeks $(0.8 \pm 0.1 \%$ versus $0.4 \pm 0.1 \%$, respectively) [38]. In our study, initial $\mathrm{HbA}_{1 \mathrm{C}}$ levels of the participants were not substantially increased $(7.0 \pm 0.3 \%)$ when compared to normal values. Thus, higher baseline levels of $\mathrm{HbA}_{1 \mathrm{C}}$ might more rapidly change by exercise than lower levels. In contrast to fasting plasma glucose, non-fasting plasma glucose levels after physical activity are reported to be rather linked to cardiovascular disease, and a doseresponse relationship was found between exercise time and post load glucose levels $[39,40]$.

\section{Blood Analysis}

We observed a slight but significant time $\mathrm{x}$ group interaction, indicating an increase in hemoglobin concentration after HIT. As a potential mechanism, reduced plasma volume might have elevated hemoglobin, as intense exercise appears to be associated with hemoconcentration [41]. However, calculated changes in plasma volume between HIT and CMT did not reach statistical significance.

\section{Limitations}

Limiting factors of our study are the small size of sub-groups (HIT,
CMT) and the duration of the intervention. Thus, the trends observed in the HIT group might turn out more favourable when implementing a larger study population and/or when the exercise training is prolonged. In addition, in this study, the participants were predominantly male. Another limiting factor is the subject selection from a pool of diabetes patients without complications for safety reasons. Therefore, our findings may be generalized to the overall diabetes population only with caution. In addition, the maximal cycle ergometry test was symptom limited, and premature termination of the tests may have led to a slight underestimation of the peak power output in some cases. However, HR max values were greater than $95 \%$ of the age predicted HR max (220age) [42].

\section{Conclusion}

The present study shows that supervised short-term exercise training (4-weeks) was capable to increase HCVR and to improve $\mathrm{VO}_{2}$ peak in patients with type 2 diabetes mellitus. These findings are of clinical relevance, as low exercise capacity predicts cardiovascular and overall mortality, and an optimal exercise strategy still needs to be found. With regard to our secondary objective, HIT is less time demanding and might demonstrate an effective alternative training strategy to CMT.

\section{Acknowledgments}

We would like to thank all the volunteers who participated in the study. Additionally, we thank the University of Innsbruck for a scholarship and for financial support of this project.

\section{References}

1. Surampudi PN, John-Kalarickal J, Fonseca VA (2009) Emerging concepts in the pathophysiology of type 2 diabetes mellitus. Mt Sinai J Med 76: 216-226.

2. Boulé NG, Kenny GP, Haddad E, Wells GA, Sigal RJ (2003) Meta-analysis of the effect of structured exercise training on cardiorespiratory fitness in Type 2 diabetes mellitus. Diabetologia 46: 1071-1081.

3. Sui X, Hooker SP, Lee IM, Church TS, Colabianchi N, et al. (2008) A prospective study of cardiorespiratory fitness and risk of type 2 diabetes in women. Diabetes Care 31: 550-555.

4. Rosengård-Bärlund M1, Bernardi L, Fagerudd J, Mäntysaari M, Af Björkesten CG, et al. (2009) Early autonomic dysfunction in type 1 diabetes: a reversible disorder? Diabetologia 52: 1164-1172.

5. Duennwald T, Bernardi L, Gordin D, Sandelin A, Syreeni A, et al. (2013) Effects of a single bout of interval hypoxia on cardiorespiratory control in patients with type 1 diabetes. Diabetes 62: 4220-4227.

6. Montserrat JM, Cochrane GM, Wolf C, Picado C, Roca J, et al. (1985) Ventilatory control in diabetes mellitus. Eur J Respir Dis 67: 112-117.

7. Nishimura M1, Miyamoto K, Suzuki A, Yamamoto H, Tsuji M, et al. (1989) Ventilatory and heart rate responses to hypoxia and hypercapnia in patients with diabetes mellitus. Thorax 44: 251-257.

8. Weisbrod CJ, Eastwood PR, O'Driscoll G, Green DJ (2005) Abnorma ventilatory responses to hypoxia in Type 2 diabetes. Diabet Med 22: 563-568.

9. Williams JG, Morris Al, Hayter RC, Ogilvie CM (1984) Respiratory responses of diabetics to hypoxia, hypercapnia, and exercise. Thorax 39: 529-534.

10. Homma I, Kageyama S, Nagai T, Taniguchi I, Sakai T, et al. (1981) Chemosensitivity in patients with diabetic neuropathy. Clin Sci (Lond) 61: 599603.

11. Pikkujämsä SM, Huikuri HV, Airaksinen KE, Rantala AO, Kauma H, et al. (1998) Heart rate variability and baroreflex sensitivity in hypertensive subjects with and without metabolic features of insulin resistance syndrome. Am J Hypertens 11 : 523-531.

12. lellamo F, Legramante JM, Massaro M, Raimondi G, Galante A (2000) Effects of a residential exercise training on baroreflex sensitivity and heart rate variability in patients with coronary artery disease: A randomized, controlled study. Circulation 102: 2588-2592. 
13. Goulopoulou S, Baynard T, Franklin RM, Fernhall BO, Jr Carhart R (2010) Exercise training improves cardiovascular autonomic modulation in response to glucose ingestion in obese adults with and without type 2 diabetes mellitus. Metabolism 59: 901-910.

14. Loimaala A, Huikuri HV, Kööbi T, Rinne M, Nenonen A, et al. (2003) Exercise training improves baroreflex sensitivity in type 2 diabetes. Diabetes 52: 18371842.

15. Colberg SR, Albright AL, Blissmer BJ, Braun B, Chasan-Taber L et al. (2010) Exercise and type 2 diabetes: American College of Sports Medicine and the American Diabetes Association: joint position statement. Exercise and type 2 diabetes. Med Sci Sports Exerc 42: 2282-2303.

16. Bacchi E, Negri C, Zanolin ME, Milanese C, Faccioli N, et al. (2012) Metabolic effects of aerobic training and resistance training in type 2 diabetic subjects: a randomized controlled trial (the RAED2 study). Diabetes Care 35: 676-682.

17. Little JP, Gillen JB, Percival ME, Safdar A, Tarnopolsky MA, et al. (2011) Lowvolume high-intensity interval training reduces hyperglycemia and increases muscle mitochondrial capacity in patients with type 2 diabetes. J Appl Physiol (1985) 111: 1554-1560

18. Terada T, Friesen A, Chahal BS, Bell GJ, McCargar LJ, et al. (2013) Feasibility and preliminary efficacy of high intensity interval training in type 2 diabetes. Diabetes Res Clin Pract 99: 120-129.

19. Bernardi L, Gabutti A, Porta C, Spicuzza L (2001) Slow breathing reduces chemoreflex response to hypoxia and hypercapnia, and increases baroreflex sensitivity. J Hypertens 19: 2221-2229.

20. Bernardi L, Passino C, Serebrovskaya Z, Serebrovskaya T, Appenzeller O (2001) Respiratory and cardiovascular adaptations to progressive hypoxia; effect of interval hypoxic training. Eur Heart J 22: 879-886.

21. Laude D, Elghozi JL, Girard A, Bellard E, Bouhaddi M, et al. (2004) Comparison of various techniques used to estimate spontaneous baroreflex sensitivity (the EuroBaVar study). Am J Physiol Regul Integr Comp Physiol 286: R226-231.

22. Bernardi L, De Barbieri G, Rosengård-Bärlund M, Mäkinen VP, Porta $C$, et al. (2010) New method to measure and improve consistency of baroreflex sensitivity values. Clin Auton Res 20: 353-361.

23. Bertinieri G, di Rienzo M, Cavallazzi A, Ferrari AU, Pedotti A, et al. (1985) A new approach to analysis of the arterial baroreflex. J Hypertens Suppl 3: S79-81.

24. Pagani M, Somers V, Furlan R, Dell'Orto S, Conway J, et al. (1988) Changes in autonomic regulation induced by physical training in mild hypertension. Hypertension 12: 600-610.

25. Pinna GD, Maestri R (2001) Reliability of transfer function estimates in cardiovascular variability analysis. Med Biol Eng Comput 39: 338-347.

26. American College of Sports Medicine (1991) Guidelines for exercise Testing and Prescription (4th edn) Lea and Febiger, Phiadelphia.

27. Borg GA (1982) Psychophysical bases of perceived exertion. Med Sci Sports Exerc 14: 377-381.

28. Dill DB, Costill DL (1974) Calculation of percentage changes in volumes of blood, plasma, and red cells in dehydration. J Appl Physiol 37: 247-248.

29. Harthmann AD, De Angelis K, Costa LP, Senador D, Schaan BD, et al. (2007) Exercise training improves arterial baro- and chemoreflex in control and diabetic rats. Auton Neurosci 133: 115-120.
30. Page MM, Watkins PJ (1978) Cardiorespiratory arrest and diabetic autonomic neuropathy. Lancet 1: 14-16.

31. Fletcher GF, Balady GJ, Amsterdam EA, Chaitman B, Eckel R, et al. (2001) Exercise standards for testing and training: a statement for healthcare professionals from the American Heart Association. Circulation 104: 16941740 .

32. Wei M, Gibbons LW, Kampert JB, Nichaman MZ, Blair SN (2000) Low cardiorespiratory fitness and physical inactivity as predictors of mortality in men with type 2 diabetes. Ann Intern Med 132: 605-611.

33. Helgerud J, Høydal K, Wang E, Karlsen T, Berg P, et al. (2007) Aerobic highintensity intervals improve VO2max more than moderate training. Med Sc Sports Exerc 39: 665-671.

34. Wisløff U, Stoylen A, Loennechen JP, Bruvold M, Rognmo Ø (2007) Superior cardiovascular effect of aerobic interval training versus moderate continuous training in heart failure patients: a randomized study. Circulation 115: 3086 3094.

35. Tjønna AE, Lee SJ, Rognmo Ø, Stølen TO, Bye A, et al. (2008) Aerobic interval training versus continuous moderate exercise as a treatment for the metabolic syndrome: a pilot study. Circulation 118: 346-354.

36. Moholdt TT, Amundsen BH, Rustad LA, Wahba A, Løvø KT et al. (2009) Aerobic interval training versus continuous moderate exercise after coronary bypass surgery: A randomized study of cardiovascular effects and quality of life. Am Heart J 158: 1031-1037.

37. Bweir S, Al-Jarrah M, Almalty AM, Maayah M, Smirnova IV, et al. (2009) Resistance exercise training lowers $\mathrm{HbA} 1 \mathrm{c}$ more than aerobic training in adults with type 2 diabetes. Diabetol Metab Syndr 1: 27.

38. Snowling NJ, Hopkins WG (2006). Effects of different modes of exercise training on glucose control and risk factors for complications in type 2 diabetic patients: a meta-analysis. Diabetes Care 29: 2518-2527.

39. Coutinho M, Gerstein HC, Wang Y, Yusuf S (1999) The relationship between glucose and incident cardiovascular events: a metaregression analysis of published data from 20 studies of 95,783 individuals followed for 12.4 years. Diabetes Care 22: 233-240.

40. Healy GN, Dunstan DW, Shaw JE, Zimmet PZ, Owen N (2006) Beneficial associations of physical activity with 2 -h but not fasting blood glucose in Australian adults: the AusDiab study. Diabetes Care 29: 2598-2604.

41. Gray AB, Telford RD, Weidemann MJ (1993) The effect of intense interva exercise on iron status parameters in trained men. Med Sci Sports Exerc 25 778-782.

42. Howley ET, Bassett DR Jr, Welch HG (1995) Criteria for maximal oxygen uptake: review and commentary. Med Sci Sports Exerc 27: 1292-1301. 